\title{
(0091) Control of Open end Induction Motor by Multi-objective GA based Selective Harmonic Elimination PWM to reduce Zero Sequence Currents and Torque Ripples
}

\author{
1st author (corresponding author) ${ }^{1 凶}$, 2nd author ${ }^{1}$, and 3 rd author ${ }^{2}$ \\ ${ }^{1}$ Universiti ..., 00000 City, State if any, Country, \\ ${ }^{2}$ Universiti ..., 00000 City, State if any, Country, \\ $\otimes_{\text {author.email@gmail.com }}$
}

\section{Abstract}

A Double inverter powered induction motor with open stator winding has few benefits, including excessive error forbearance functionality, great flexibility and lesser rating of dc input voltage etc. For this Configuration, two types of Modules can implement they are Non-isolated DC link and Isolated DC link. In these two, Non-isolated DC link is a good choice due to effective DC-link utilization and ruggedness, which is very beneficial in many applications. However, this module produces more zero sequence currents (Z-SC) by means of common mode (CMMD) voltage, which flows through $D c$ bus. The circulation of Z-SC must as little as feasible since it merely does rise the amplitude of currents in all phases. High ripple frequency of currents and torque, In addition resulting extra loss, which not alone reduces the efficiency, but loading ability and quickens the aging of drive. The triplen harmonics can denote meticulously as harmonics with integer of three times the frequency at fundamental, when they are in Phase in all Phases forms the Z-SC. In this paper, a novel SHE method is chosen to target triplen harmonics in Single DC Source Module (Non- isolated) and holding preferred fundamental quantity, which aids in improving the torque handling ability of the motor. In addition, the investigation of dual inverter fed OEW-IM with both common DC source as well as separate DC sources also explored by SHE for different number of switching angles and variable Modulation Index (MI) towards the torque ripples and Z-SC reduction are given. The foremost challenge related with SHE method is that resolving a set of higher order nonlinear equations with number of variables. A Multi-objective GA method provided for that challenge which effects the reduction in Z-SC so that torque ripples will be minimised. Moreover, the novel SHE method reduces more number of harmonics than the conventional SHE, which further decreases TH-D with decent fundamental quantity. For validation, the essential mathematical formulations and simulation results presented.

Keywords: Open-end winding induction machine (OEW-IM), Zero sequence currents (Z-SC), Torque ripple, Selective harmonic elimination (SHE), Triplen
Harmonics.

\section{Introduction}

Compared by the customary single end power supply, the benefits of the OEW-IM with dual end inverters are the regulator of great flexibility, the fault forbearance and redundancy of arrangement [1] . The output voltage could be two times higher than a single inverter [2]. Dual inverter OEW-IM arrangement compared with the midpoint clamped $3 \mathrm{~L}$ inverter, it just not simply excludes necessity of Clamping diodes, decreases price, no DC mid-point, and there is no midpoint equilibrium difficulty [3]. Related with the FC $3 \mathrm{~L}$ inverter, reduces the capacitance requests [1]. Furthermore, double inverter OEW-IM able to appreciate the hydrides drive with diverse sources of energy; therefore, it is a superlative dynamic structure for modern energy automobiles [2].

OEW-IM can run through a single conjoint dc bus or autonomous dc bus, as given in fig.1.b.If the inverters feeding machine undertake the independent configuration of dc bus, fig.1.a. There is not any circlet for Z-SC between the inverters. Nevertheless, two inverters output side yet forms motor shaft voltage, it's possibly will yields current through shaft and stimulus in effect of motor bearings life span. Moreover, the isolated DC bus configuration needs two separate batteries, this turns to the aforementioned restricted applications. On the other side, the inverters arrangement with shared single DC bus scheme entails a single source, which make simpler hardware design and simplifies employment of the scheme. However, single dc bus permits an occurrence of zero sequence paths inside the primary circuit. It abolishes and restraint that the addition of 3 phase currents results zero, if the actual procedures has not taken to regulate the circulation it may produce greater Z-SC, leading to more 
produces a high in the motor phase windings, which is

losses in motor and ripples in motor torque, it's not advantageous to the Improvement of running enactment of the machine control scheme [4]. Hence, the Z-SC issue dominance in the OEW-IM arrangement by a single shared DC bus is bottleneck problem that worries the usage of this structure [5-8].

Furthermore, the motor lifespan will decrease when the motor is not capable to tolerate the unnecessary temperature produced for system to operate with torque at full load. In order to suppress Z-SC suggestions a common mode chokes are used [9], to compute the error voltage the current control loop is altered [10], PWM schemes which does not produce zero sequence voltages [11] then control principles to reduce Z-SC [12]. The modelling of an OEW-IM with stationary frame given by equations (a)-(e).

The two foremost reasons on behalf of circulating currents are voltage drops at semiconductor devices, which carries current and dead time castoff to overcome occurrence of short circuit in Pulse Width Modulated drives. The said things identified as reason for distortion in waveform of a traditional Pulse Width Modulated ac drives [13], [14] also could leads instabilities and voltage loss. More than a number of solutions has suggested in recompensing of these distortions [15]-[20] in traditional drives with

connections. Further, dual inverter is not upfront in the occurrence of the currents Z-SC circulating in inverters. This current rises the stresses in current and increases the inverters conduction losses across their switching devices. High amount of Z-SC circulating (Z-SCC) are challenging because they push operators to increase the size of inverters and lessens efficiency of inverter [21]-[23]

The efficacy of the suggested Z-SCC reduction technique, by a Selective Harmonic Elimination PWM (SHE-PWM) given in this paper [24]-[30]. Revised the fundamental principles of SHE-PWM for a dual VSI fed OEWIM, and then, the recommended SHE method established for dual inverter fed OEW$\mathrm{IM}$ and adjusts further to permit for the removal of Z-SCC in an OEW-IM that lessens the ripple content in Motor Torque. An Investigation of Z-SCC, Toque ripple and $\mathrm{TH}-\mathrm{D}$ given for different modulation indices and number of switching angles. The achievability of the suggested methodology in removing harmonics of inverters voltages, reducing Z-SCC \& Torque Ripples established by the results.

\section{II.Problem Formulation of Open Ended Induction Motor Fed by Dual inverter}

In OEW-IM, the Sum of the motor phase voltages never equal to zero, henceforth here exists a zero sequence voltages. Existence of zero sequence voltages harmful to the switching devices and the motor itself. To overwhelm the zero-sequence components in the motor phases, each inverter is functioned with an isolated DC power supply, but it is not good for hardware enactment. Therefore, the said difficult arises when two inverters operates by a single DC source which shown in fig 1 .

Due to the fact that the addition of OEW-IM $3 \varnothing$ voltages certainly not zero, henceforth here the Zero Sequence Voltages (ZSVs) occurs and these ZSVs results a large Z-SC in Phase windings of machine and this is unsafe to switching devices and the machine as well. In or der to avoid these Zero Sequence elements in phases of motor, a separate dc sources are connected to each inverter, but it is not good for hardware enactment. Therefore, the said difficult arises when two inverters operates with a common dc single source which displayed by Fig.1.

In OEW-IM arrangement with Shared single Dc bus, the voltage trajectories engendered through inverters VSI-1 \& VSI-2 be stated as

Where $V_{10}, V_{20}$ and $V_{30}$ represents leg voltages of phases $A, B$ and $C$ correspondingly. So description for switching characteristic $S_{x y}=1(x=$ a phase or $b$ phase or $c$ phase; $y=1$ or 2 ) signifies $O N$ position of top switch of particular phase, while $S_{x y}$ $=0$ indicates OFF position of top switch of particular phase. Similarly, the voltage vector on motor windings be represented by two-inverter voltage vector $V_{s 1}, V_{s 2}$ difference form, namely

$$
\mathrm{V}_{\mathrm{s}}=\mathrm{V}_{\mathrm{s} 1}-\mathrm{V}_{\mathrm{s} 2}
$$

As both the inverters (Inv-1 \& Inv-2) are coupled to a share one DC voltage source $\mathrm{V}_{\mathrm{dc}}$ The voltage delivered by an inverters, Inv-1 \& Inv-2 can be known with the depictions ' + ' specifies on '-' specifies off situations of top switch in inverter leg. These devices in inverters operates by complementary rule, if switches at top is on, then lower one in the same leg should off and converse. The voltage magnitudes marked by trios containing ' + ' and '-' signifying the locations of switch at a-phase, b-phase, c-phase correspondingly. An instance take trio $(-++)$ specifies voltage magnitude for a phase top one is off and b \& c phases lower ones on. The maximum probable states of all the switches grouping in each phase when top and lower switches are in on and off positions given in Table 1.

Amid of all eight states of each inverter switches groupings, six are active states of voltages with a supply voltage magnitude in this situation $V_{d c}$ and remaining two are null voltages. Taking an example, state $1-4$ ' of the arrangement is attained by switching 

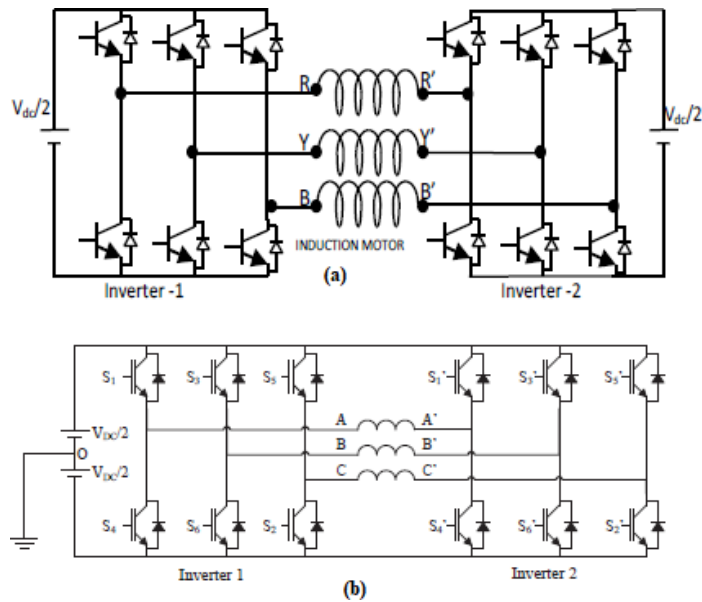

Figure 1: OEW-IM structure with (a) Isolated DC Links (b) Common DC Link

of the voltage of 'Inv1' and 4' of 'Inv2'. It can perceived that excluding the maximum value of voltage magnitude all remaining voltages of the given structure can comprehended in many ways.

The dual inverter (Fig. 2) and its modulation scheme designated in [31]. The two inverters modulated such that the instantaneous common mode voltages at each of the machine's two terminals are constant and equal.

Dual Inverter (fig.1) with control scheme designated in [31] and these inverters controlled in such a way their instantaneous CMMD voltages of machine both ends should be constant \& equal. The CMMD volt-

$\begin{array}{ccc}\begin{array}{c}\text { Inverter-1 } \\ \text { Positions }\end{array} & \text { switches in on Position } & \text { Inverter-2 } \\ 0(---) & \mathrm{S}_{12}, \mathrm{~S}_{14}, \mathrm{~S}_{16} & 0^{\prime}(---) \\ 1(+--) & \mathrm{S}_{11}, \mathrm{~S}_{14}, \mathrm{~S}_{16} & 1^{\prime}(+--) \\ 2(++-) & \mathrm{S}_{11}, \mathrm{~S}_{13}, \mathrm{~S}_{16} & 2^{\prime}(++-) \\ 3(-+-) & \mathrm{S}_{12}, \mathrm{~S}_{13}, \mathrm{~S}_{16} & 3^{\prime}(-+-) \\ 4(-++) & \mathrm{S}_{12}, \mathrm{~S}_{13}, \mathrm{~S}_{15} & 4^{\prime}(-++) \\ 5(--+) & \mathrm{S}_{12}, \mathrm{~S}_{14}, \mathrm{~S}_{15} & 5^{\prime}(--+) \\ 6(+-+) & \mathrm{S}_{11}, \mathrm{~S}_{14}, \mathrm{~S}_{15} & 6^{\prime}(+-+) \\ 7(+++) & \mathrm{S}_{11}, \mathrm{~S}_{13}, \mathrm{~S}_{15} & 7^{\prime}(+++)\end{array}$

Table 1: Switching combinations to produce different inverter voltage magnitudes

ages of machine both ends given as $\mathrm{V}_{\mathrm{C} 1 \mathrm{~N}}, \mathrm{~V}_{\mathrm{C} 2 \mathrm{~N}}$

$\mathrm{V}_{\mathrm{c} 1 \mathrm{~N}}=\mathrm{V}_{\mathrm{A} 1 \mathrm{~N}}+\mathrm{V}_{\mathrm{B} 1 \mathrm{~N}}+\mathrm{V}_{\mathrm{C} 1 \mathrm{~N}} / 3$

(3)

$\mathrm{V}_{\mathrm{C} 2 \mathrm{~N}}=\mathrm{V}_{\mathrm{A} 2 \mathrm{~N}}+\mathrm{V}_{\mathrm{B} 2 \mathrm{~N}}+\mathrm{V}_{\mathrm{C} 2 \mathrm{~N}} / 3$

(4)

Where $\mathrm{V}_{\mathrm{A} 1 \mathrm{~N}}, \mathrm{~V}_{\mathrm{B} 1 \mathrm{~N}}, \mathrm{~V}_{\mathrm{C} 1 \mathrm{~N}}, \mathrm{~V}_{\mathrm{A} 2 \mathrm{~N}}, \mathrm{~V}_{\mathrm{B} 2 \mathrm{~N}}, \mathrm{~V}_{\mathrm{C} 2 \mathrm{~N}}$ represents the pole or leg voltages of inv1 \& inv2 respectively, and $\mathrm{V}_{\mathrm{C} 1 \mathrm{~N}}$ say $\mathrm{CMMD}$ of 'Inv1' \& $\mathrm{V}_{\mathrm{C} 2 \mathrm{~N}}$ say $\mathrm{CMMD}$ of

'Inv2'. Thus, the CMMD acting through stator Windings given by $\mathrm{V}_{\mathrm{cm}}=\mathrm{Vc}_{1 \mathrm{~N}}-\mathrm{V}_{2 \mathrm{~N}}$. For all the switching

$0-7^{\prime}$

switches in on Position

$3-7^{\prime}$

$$
\begin{aligned}
& \mathrm{S}_{22}, \mathrm{~S}_{24}, \mathrm{~S}_{26} \\
& \mathrm{~S}_{21}, \mathrm{~S}_{24}, \mathrm{~S}_{26} \\
& \mathrm{~S}_{21}, \mathrm{~S}_{23}, \mathrm{~S}_{26} \\
& \mathrm{~S}_{22}, \mathrm{~S}_{23}, \mathrm{~S}_{26} \\
& \mathrm{~S}_{22}, \mathrm{~S}_{23}, \mathrm{~S}_{25} \\
& \mathrm{~S}_{22}, \mathrm{~S}_{24}, \mathrm{~S}_{25} \\
& \mathrm{~S}_{21}, \mathrm{~S}_{24}, \mathrm{~S}_{25} \\
& \mathrm{~S}_{21}, \mathrm{~S}_{23}, \mathrm{~S}_{25}
\end{aligned}
$$

Common Mode (CMMD) Voltages

Table 2: CMMD Voltages of machine winding phases

- combinations of 'Inv1' \& 'Inv2', the CMMD voltages acting through phase windings of a motor shown by above Table2. From this table it can understand that it has overall twenty switch groupings so they produces no CMMD voltages at motor phase windings [32].These grouping switches will not yields any circulation current yet non isolated dc supply feeds to power inverters 'Inv1' \& 'Inv2'. 


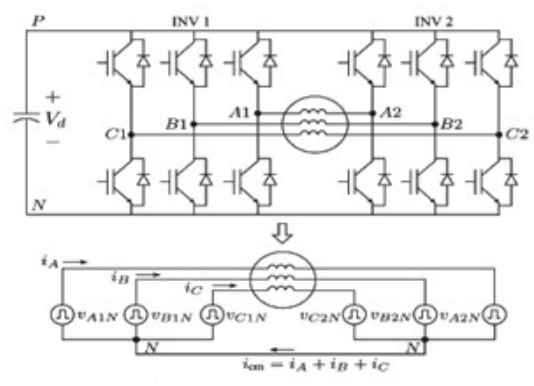

Figure 2: Equivalent circuit of OEW-IM with Zero sequence currents

In fig.2, it shows Z-sc flow over the dc supply link amongst dual inverters. Equation for Z-SC model stated as follows [33].

$i o=\frac{V o}{R s+j w l o}$

The OEW-IM arrangement zero sequence voltage given by equation (6.a).

$V o=\frac{1}{3}((V a 10-V a 2 o)+(V b 10-V b 2 o)+(V c 10-$

Where $R_{\mathrm{s}}$ denotes winding resistance stator, $L_{0}$ denotes winding leakage inductance of stator and its equivalent to zero sequence inductance. Clearly, the extent of Z-SC be subject to the amount of zero (ZSV) sequence voltage. So, these voltages mostly from motor and inverter itself. The ZSV produced by control strategy, voltage drop and dead time of switches, so on. [35], the motor back EMF (BEMF) consists harmonics owing to spatial harmonics of a machine. In several situations, sinusoidal BEMF presumed and the harmonics unnoticed. Nevertheless, the third harmonic cannot ignored in OEW with a common single dc supply arrangement since it comprises zero sequence. The fundamental $3 \varnothing \mathrm{BEMF}$ pronounced as follows.

$$
\left[\begin{array}{c}
V_{e m f 1, a} \\
V_{e m f 1, b} \\
V_{e m f 1, c}
\end{array}\right]=\left[\begin{array}{c}
V_{e m f 1} \sin (\phi+\pi) \\
V_{e m f 1} \sin \left((\phi+\pi)-\frac{2 \pi}{3}\right) \\
V_{e m f 1} \sin \left((\phi+\pi)-\frac{4 \pi}{3}\right)
\end{array}\right]
$$

Where Vemf 1 is the of the fundamental component amplitude of BEMF. Then, the $3^{\text {rd }}$ harmonic elements of $3 \varnothing \mathrm{BEMF}$ designated as follows by equation( 7 )

$$
\left[\begin{array}{l}
V_{e m f 1, a} \\
V_{e m f 1, b} \\
V_{e m f 1, c}
\end{array}\right]=\left[\begin{array}{c}
V_{e m f 1} \sin (3(\phi+\pi)) \\
V_{e m f 1} \sin \left(3((\phi+\pi))-\frac{2 \pi}{3}\right) \\
V_{e m f 1} \sin \left(3((\phi+\pi))-\frac{4 \pi}{3}\right)
\end{array}\right]
$$

Where Vemf 3 represents $3^{\text {rd }}$ harmonic amplitude of the BEMF. The BEMF zero sequence component shown in equation (8)

$$
\begin{aligned}
& V_{e m f, 0}=\sum_{i=a, b, c}\left(V_{e m f 1, i}+V_{e m f 3, i}\right)= \\
& -3 V_{e m f 3}\left(3 \theta_{e}+\theta_{3}\right)(8)
\end{aligned}
$$

The fundamental components voids in (8) and BEMF zero sequence component contains $3^{\text {rd }}$ harmonic components. Below figure shows, waveforms for BEMF Zero sequence component and initiated Z-SC. It is tough to recompense vemf 0 through feed forward to the voltage reference for the reason that its magnitude and phase offset are typically unidentified.

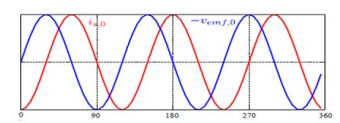

Figure 3: Zero sequence voltage and current due to $3^{\text {rd }}$ harmonic of back EMF

\section{III.CONCEPTION OF MULTIOBJECTIVE GA BASED SHE PWM}

This section analyses the principle of the SHE-PWM dual VSI, in order to produce a pulse width modulation signals, which can remove harmonics from output voltage waveform. To achieve this the following mategtodone: i) (B.efjne a set of significant commutating angles for number of equations that obtained from theory of Fourier analysis and ii) usage of the calculated angles and several equilibriums to build definite pattern.

The Fourier series extension of voltage wave by a general SHE PWM given by equation (9.a).

$V(\omega t)=\sum_{n=1}^{\infty}\left(a_{n} \cos (n \omega t)+b_{n} \sin (n \omega t)\right)$

Pertaining to PWM scheme the features of odd functions \& $\mathrm{QWS}, \mathrm{a}_{\mathrm{n}}=0$, for all $\mathrm{n}$, and voltage wave equation modifies as equation (9.b)

$V(\omega t)=\sum_{n=1}^{\infty} b_{n} \sin (n \omega t)$

A generalised equation of $b_{n}$ for ' $N$ ' number of commutation angles for odd values of $\mathrm{n}$ shown by equation (10)

$b_{n}=\frac{2 V_{d c}}{n \pi}\left(2 \sum_{j=1}^{N}(-1)^{j-1} \cos n \alpha_{j}-1\right)$

The SHE procedure needs $\mathrm{N}$ commutation angles $\alpha_{1}, \alpha_{2} \ldots, \alpha_{N}$, in first quarter period for individual inverter. One angle in $\mathrm{N}$ no. of angles controls the fundamental component, then remaining angles i.e. $\mathrm{N}-1$ used to remove $\mathrm{N}-1$ number of harmonics in inverter [34], the chopping angles desired to removes lower order odd number harmonics for a $3 \varnothing$ VSI like $3^{\text {rd }}, 5^{\text {th }}$, and $7^{\text {th }}$ etc. Which quantified in amid of zero and $\pi / 2$.

The general equations to eliminate $\mathrm{N}-1$ number of harmonics obtainable in [33] and [34] can given by equation (11) \& (12).

$-\sum_{j=1}^{N}(-1)^{j} \cos \left(\alpha_{j}\right)=\frac{2+M \pi}{4}$ 
$-\sum_{j=1}^{N}(-1)^{j} \cos \left(n \alpha_{j}\right)=0.5$

If $\mathrm{n}=3,5,7, \ldots .3 \mathrm{~N}-1$, then

Ifn $=3,5,7, \ldots . .3 N-1$, then $\alpha_{1}<\alpha_{2}<\alpha_{3}<$

..... $<\alpha_{N}<\frac{\pi}{2}$

Numerous multi objective issues necessitating concurrent optimization at more than a few challenging objectives. Properly, it can detailed, supposed to find $\bar{x}=\left(x_{1}, x_{2}, x_{3} \ldots \ldots x_{n}\right)$

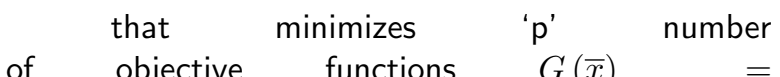
$\left(g 1\left(x_{1}\right), g_{1}\left(x_{1}\right), g_{2}\left(x_{2}\right), g_{3}\left(x_{3}\right) \ldots \ldots . . g_{n}\left(x_{n}\right)\right)$ contained by a viable domain. Usually, the solution is not even one but many called a Pareto optimal set. To a particular multi objective problem $\mathrm{G}(\mathrm{x})$, the Pareto-optimal set $\mathrm{P}$ defined as $P=\left\{x \in \exists x^{\prime} \in \cup: F\left(x^{\prime}\right) \leq F(x)\right\}$ The techniques for an optimization usually tries for determining a specified number of Pareto-optimal solutions, which are reliably disseminated in the Pareto-optimal set, these elucidations, affords choice maker adequate understanding the problem keenly for a final decision. Conversely, an a priori expression of the predilections to the essential objectives, which is often tough to choose in advance. In addition, these techniques can merely discover one solution at a time. Further solutions could not attain without number of times computations with free constraints reset. In better, GAs genetic algorithms preserve a population as well as a result can hunt for various liberated solutions concurrently as shown in fig 4. GAs capability for catching various set of solutions in one run and its exception on or after mandate to impartial partiality statistics that concentrates this instant benefit over above-mentioned methods. An MOGA characterized by its fitness consignment and multiplicity conservation approach. Hereafter, to optimize the no. of switching angles concurrently by means of evolutionary methodology, this paper affords a method entitled as genetic algorithm with multi objective for SHE PWM applied to Dual inverter fed OEW-IM.

\section{PROPOSED SCHEME FOR MODELLING OF DOUBLE VSI FED OEW-IM}

From previous sections it can concludes that the tripled harmonics be present, when single source based Dual inverter fed to OEW-IM they leads to Z-SC and then reasons Torque Ripples. Desired shape of the output voltage from two inverters with the preferred harmonics content and amplitude of the main harmonic factor obtained by the scheming of the switching angles in the full choice of the amplitude MI. Maximum index is unique for the numerous wide variety of angles. With the growing of the modulation index, time range between commuta-

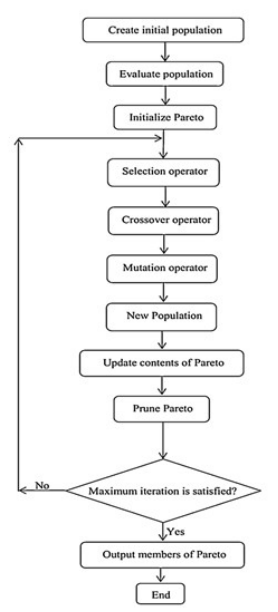

Figure 4: The flowchart of multi-objective genetic algorithm

tions is getting shorter. Because to remedy complexity of equations to find switching instants, the range of switching angles is typically stored low to make the calculations simple. However, to be able to successfully lessen the harmonics content material of two inverters output waveform and generate higher pleasant spectrum through removal of unique decrease order harmonics, TH-D and torque ripples discount, greater wide variety of switching angles taken for two inverters. Hence, this case examine used, $\mathrm{N}$ values three and five, number of switching angles for Dual inverters fed OEW-IM.

For a Dual VSI, there are VSIs distributing by DC bus at source side and serving OEW-IM at load end. The suggested methodology plays to produce optimized gating forms so that a hard and fast of harmonics at lower frequency is reduced in OEW-IM .In different words , determining gating styles for each inverter in order that a targeted harmonics engendered with the aid of the 2 converters adds as much as zero. The inclusive ac voltages will not now comprise undesirable harmonics, and yet those harmonics can exist on each inverter output. It is not like the traditional technique wherein targeted annoying harmonics reduced within output voltage of individual converter.

In this technique, same quantity $(\mathrm{N}=3 \& 5)$ of commutation angles executed to every inverter, same as the case of traditional method, and each inverter is functioned with identical switching frequency. The predominant distinction is that the pulse styles of every inverter module are extraordinary and every module is needed to produce essential issue with the preferred modulation index $M$, it has $2^{*}(N-1)$ degrees of freedom (DOFs) to remove harmonics better than the conventional case $\mathrm{N}-1$ harmonics. These sorts 
the corresponding $f_{s}$ for general voltages of inverter more than that what can generated with traditional technique then as a result permits extra harmonics to cast off. It must note that, even though gating forms are dissimilar for every inverter running with suggested modulation method, the fundamental factor and wide variety of commutating angles are identical.

\section{Case (i): Proposed SHE with three switching an- gles}

Consider the case of a dual inverter in which that preferred the range of switching angles in each inverter Modulation sample be three (i.e. $\mathrm{N}=3$ ). The traditional Modulation method, in which every inverter functioned with an equal sample as the other, consequences the best two level of harmonics removed, as an instance, $3^{\text {rd }} \& 5^{\text {th }}$ [by equation (11)]. However, inside the proposed technique, the $3^{\text {rd }}, 5^{\text {th }}, 7^{\text {th }}$, \& $9^{\text {th }}$ harmonics add as much as zero in the total ac voltage that is double the instances range of harmonics than a traditional method.

With $\mathrm{N}=3$, set of equations that must be resolved to determine angles for two Inverters are given by equation (13) Case (ii): Proposed SHE with
$\operatorname{Cos}\left(1 \alpha_{1} A\right)-\operatorname{Cos}\left(1 \alpha_{2} A\right)-\operatorname{Cos}\left(1 \alpha_{3} A\right)-$

$\operatorname{Cos}\left(1 \alpha_{4} A\right)-\operatorname{Cos}\left(1 \alpha_{5} A\right)=\frac{(2+M \pi)}{4}$

$\operatorname{Cos}\left(1 \alpha_{1} B\right)-\operatorname{Cos}\left(1 \alpha_{2} B\right)+\operatorname{Cos}\left(1 \alpha_{3} B\right)-$

$\operatorname{Cos}\left(1 \alpha_{4} B\right)+\operatorname{Cos}\left(1 \alpha_{5} B\right)=\frac{(2+M \pi)}{4}$

$\left[\operatorname{Cos}\left(3 \alpha_{1}^{A}\right)-\operatorname{Cos}\left(3 \alpha_{2}^{A}\right)+\operatorname{Cos}\left(3 \alpha_{3}^{A}\right)-\operatorname{Cos}\left(3 \alpha_{4}^{A}\right)+\operatorname{Cos}\left(3 \alpha_{5}^{A}\right)\right]$

$\left[\operatorname{Cos}\left(3 \alpha_{1}^{B}\right)-\operatorname{Cos}\left(3 \alpha_{2}^{B}\right)+\operatorname{Cos}\left(3 \alpha_{3}^{B}\right)-\operatorname{Cos}\left(3 \alpha_{4}^{B}\right)+\operatorname{Cos}\left(3 \alpha_{5}^{B}\right)\right]$

$1\left[\operatorname{Cos}\left(5 \alpha_{1}^{A}\right)-\operatorname{Cos}\left(5 \alpha_{2}^{A}\right)+\operatorname{Cos}\left(5 \alpha_{3}^{A}\right)-\operatorname{Cos}\left(5 \alpha_{4}^{A}\right)+\operatorname{Cos}\left(5 \alpha_{5}^{A}\right)\right]$

$\left[\operatorname{Cos}\left(5 \alpha_{1}^{B}\right)-\operatorname{Cos}\left(5 \alpha_{2}^{B}\right)+\operatorname{Cos}\left(5 \alpha_{3}^{B}\right)-\operatorname{Cos}\left(5 \alpha_{4}^{B}\right)+\operatorname{Cos}\left(5 \alpha_{5}^{B}\right)\right]$

$\left[\operatorname{Cos}\left(7 \alpha_{1}^{A}\right)-\operatorname{Cos}\left(7 \alpha_{2}^{A}\right)+\operatorname{Cos}\left(7 \alpha_{3}^{A}\right)-\operatorname{Cos}\left(7 \alpha_{4}^{A}\right)+\operatorname{Cos}\left(7 \alpha_{5}^{A}\right)\right]$

$\left[\operatorname{Cos}\left(7 \alpha_{1}^{B}\right)-\operatorname{Cos}\left(7 \alpha_{2}^{B}\right)+\operatorname{Cos}\left(7 \alpha_{3}^{B}\right)-\operatorname{Cos}\left(7 \alpha_{4}^{B}\right)+\operatorname{Cos}\left(7 \alpha_{5}^{B}\right)\right]$ 1

$\left[\operatorname{Cos}\left(9 \alpha_{1}^{A}\right)-\operatorname{Cos}\left(9 \alpha_{2}^{A}\right)+\operatorname{Cos}\left(9 \alpha_{3}^{A}\right)-\operatorname{Cos}\left(9 \alpha_{4}^{A}\right)+\operatorname{Cos}\left(9 \alpha_{5}^{A}\right)\right]$ $\left[\operatorname{Cos}\left(9 \alpha_{1}^{B}\right)-\operatorname{Cos}\left(9 \alpha_{2}^{B}\right)+\operatorname{Cos}\left(9 \alpha_{3}^{B}\right)-\operatorname{Cos}\left(9 \alpha_{4}^{B}\right)+\operatorname{Cos}\left(9 \alpha_{5}^{B}\right)\right]$ 1

$\left[\operatorname{Cos}\left(11 \alpha_{1}^{A}\right)-\operatorname{Cos}\left(11 \alpha_{2}^{A}\right)+\operatorname{Cos}\left(11 \alpha_{3}^{A}\right)-\operatorname{Cos}\left(11 \alpha_{4}^{A}\right)+\operatorname{Cos}(110\right.$

$\left[\operatorname{Cos}\left(11 \alpha_{1}^{B}\right)-\operatorname{Cos}\left(11 \alpha_{2}^{B}\right)+\operatorname{Cos}\left(11 \alpha_{3}^{B}\right)-\operatorname{Cos}\left(11 \alpha_{4}^{B}\right)+\operatorname{Cos}(11\right.$ 1

$\left[\operatorname{Cos}\left(13 \alpha_{1}^{A}\right)-\operatorname{Cos}\left(13 \alpha_{2}^{A}\right)+\operatorname{Cos}\left(13 \alpha_{3}^{A}\right)-\operatorname{Cos}\left(13 \alpha_{4}^{A}\right)+\operatorname{Cos}(13 \alpha\right.$ $\left[\operatorname{Cos}\left(13 \alpha_{1}^{B}\right)-\operatorname{Cos}\left(13 \alpha_{2}^{B}\right)+\operatorname{Cos}\left(13 \alpha_{3}^{B}\right)-\operatorname{Cos}\left(13 \alpha_{4}^{B}\right)+\operatorname{Cos}(13\right.$ 1

$\left[\operatorname{Cos}\left(15 \alpha_{1}^{A}\right)-\operatorname{Cos}\left(15 \alpha_{2}^{A}\right)+\operatorname{Cos}\left(15 \alpha_{3}^{A}\right)-\operatorname{Cos}\left(15 \alpha_{4}^{A}\right)+\operatorname{Cos}(15\right.$

$\operatorname{Cos}\left(15 \alpha_{1}^{B}\right)-\operatorname{Cos}\left(15 \alpha_{2}^{B}\right)+\operatorname{Cos}\left(15 \alpha_{3}^{B}\right)-\operatorname{Cos}\left(15 \alpha_{4}^{B}\right)+\operatorname{Cos}(15$

\section{Conventional Proposed Conventiontal Proposed SHE PWM}

SHE PWM SHE PWM

SHE PWMLCos $\left(17 \alpha_{1}^{A}\right)-\operatorname{Cos}\left(17 \alpha_{2}^{A}\right)+\operatorname{Cos}\left(17 \alpha_{3}^{A}\right)-\operatorname{Cos}\left(17 \alpha_{4}^{A}\right)+\operatorname{Cos}(17 \mathrm{C}$

$\begin{array}{cccc}1 & 0.2 & 0.68 & 0.5 \\ 2 & 0.4 & 0.62 & 0.48 \\ 3 & 0.6 & 0.59 & 0.46 \\ 4 & 0.8 & 0.58 & 0.42 \\ 5 & 1 & 0.55 & 0.37 \\ 6 & 1.2 & 0.53 & 0.36\end{array}$

11.5

9.2

7.8

$\left[\operatorname{Cos}\left(17 \alpha_{1}^{B}\right) \frac{7}{5} \cdot \operatorname{Cos}\left(17 \alpha_{2}^{B}\right)+\operatorname{Cos}\left(17 \alpha_{3}^{B}\right)-\operatorname{Cos}\left(17 \alpha_{4}^{B}\right)+\operatorname{Cos}(17\right.$ 1

6.65 Where $\alpha_{1}^{A}, \alpha_{2}^{A} 2.93, \alpha_{4}^{A}, \alpha_{5}^{A}$ \&amp; $\alpha_{1}^{B}, \alpha_{2}^{B}, \alpha_{3}^{B}, \alpha_{4}^{B}, \alpha_{5}^{B}$

4.95 are switching angles for Inv-1 and Inv-2 correspond-

4.75 ingly, for $\mathrm{N}=\$$.16ith different range of Modulation Indices the optimal values of noteworthy parameters shown in the below table. V. Simulation Results

Table 3: MI Vs THD and ZSC with three switching angles

\section{S.No MI THD (\%) ZSC (Amps)}

\section{Five switching angles}

Consider the case of a dual inverter ,it is preferred that a wide variety of switching angles in individual inverter modulation be $\mathrm{N}=5$. In a PWM traditional methodology, the two inverters are functioned individually with identical samples. As an alternative, now most effective number of harmonics are being removed, as the 5th and 7th [by equation (11)].Conversely, in the suggested method, the 3rd,5th,7th,11th,13th,15th,17th \& 19th harmonics appears as much as zero in the overall output voltage this is doubles than the quantity of harmonics that may remove with the traditional method.

For $N=5$, the expressions that need to resolve for obtaining both inverters (1\&2) angles are

$\begin{array}{cccccc} & & \begin{array}{c}\text { Conve-ntional } \\ \text { SHE PWM }\end{array} & \begin{array}{c}\text { Proposed } \\ \text { SHE PWM }\end{array} & \begin{array}{c}\text { Conventional } \\ \text { SHE PWM }\end{array} & \begin{array}{c}\text { Propose } \\ \text { SHE PW }\end{array} \\ 1 & 0.2 & 0.6 & 0.4 & 8.35 & 5.2 \\ 2 & 0.4 & 0.62 & 0.48 & 6.29 & 4.6 \\ 3 & 0.6 & 0.59 & 0.46 & 4.78 & 2.8 \\ 4 & 0.8 & 0.58 & 0.42 & 3.82 & 1.9 \\ 5 & 1 & 0.55 & 0.37 & 3.5 & 0.4 \\ 6 & 1.2 & 0.53 & 0.36 & 2.89 & 0.38\end{array}$

Table 4: MI Vs THD and ZSC with Five switching angles

To confirm the proposed SHE-PWM approach, Dual inverter OEW-IM has simulated in MatlabSimulink. In this paper by means of fixing the non- 
linear trigonometric equations using Multi Objective $\mathrm{GA}$, appropriate switching instances for the Inverters legs with Common DC input voltage and separate DC sources have completed. The major goal of this scheme is to lessen the Zero Sequence currents and Minimising Torque ripple at a nominal value via disposing of triplen Harmonics and decreasing the TH-D of Dual inverter voltages. The Simulink version for the scheme demonstrated in Fig 6.a \& 6.b, at the same time as the parameter values for probable $\mathrm{MI}$ values given in above Tables $3 \& 4$.

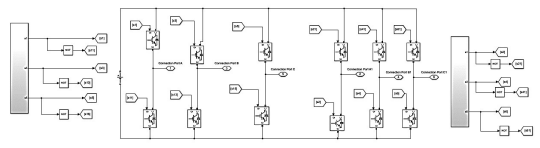

Figure 5: a.Simulink model for double inverter with non-isolated or single dc Source

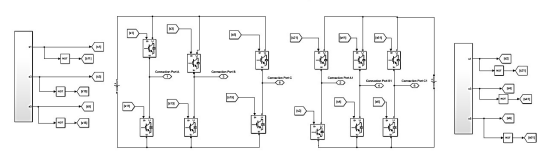

Figure 6: b.Simulink model for double inverter with Isolated DC Sources

Figure 7-12 illustrates simulation outcomes of Line Voltages, FFT evaluation of dual inverter voltages, Z$\mathrm{SC}$, and torque at $50 \mathrm{~N}-\mathrm{m}$ given load torque at rated speed provided whilst the Dual inverter tested With OEW-IM. In addition, the simulation parameters on this situation listed in Table 5. The line-line voltages, Z-SC and Torque Ripples of Dual inverter with unity modulation index proven in Fig. 6, 7\& 8, correspondingly. As FFT spectrums of output $A C$ voltages of Dual Inverter illustrates in Fig. 9, Triple order harmonic such as $3^{\text {rd }}$ and $9^{\text {th }}$ have removed whilst $\mathrm{N}=3$ and $3^{\text {rd }}, 9^{\text {th }} \& 15^{\text {th }}$ have eliminated when $N=5$ absolutely due to proper switching angles and input DC voltage. Fig. 7.a, b displays the simulation results with $3^{\text {rd }}$ harmonic reduction and FFT investigation is on condition that in Fig.8a,b for Proposed SHE manage Dual inverter fed OEW-IM with Common DC supply and Separate resources respectively. It indicates that, the proposed scheme for double inverter with isolated dc sources can able to reduce the $3^{\text {rd }}$ harmonics. So, obvious Z-SC decreased to $1.2 \mathrm{Amps}$ with 3 angles but for independent DC sources case the 3rd harmonics reduced to 0.7 amps further so Z-SC obviously gets rid off and the ripples in torque additionally decreased shown in fig.9a,b. Mainly current and next back emf features the torque. Henceforth, in the cur-

$\begin{array}{cc}\begin{array}{c}\text { DC source voltage } \\ \text { (Vdc) }\end{array} & 400 \mathrm{~V} \\ \text { Stator resistance, Rs } & 0.44 \Omega \\ \text { Rotor resistance, Rpr } & 0.82 \Omega \\ \quad \text { Statorleakage } & 0.75 \Omega \\ \text { inductance, Xls } & \\ \quad \text { Rotor leakage } & 0.75 \Omega \\ \text { inductance ,Xlpr } & \\ \quad \text { Mutual } & 26.13 \Omega \\ \text { Inductance,Xm } & \\ \text { Motor Inertia ,J } & 0.09 \Omega \\ \text { No. of Poles,P } & 4 \\ \text { Rated frequency,fs } & 50 \mathrm{~Hz}\end{array}$

Table 5: Parameters used in the Dual Inverter Fed OEW-IM with Single DC source

rents without harmonic elimination, the intended excessive frequency torque is visible. Concentrating on overall harmonic content of inverter voltages proven in Figures.7, 8, 9 it may be determined that the TH-D is low and the lower order harmonics reduced.

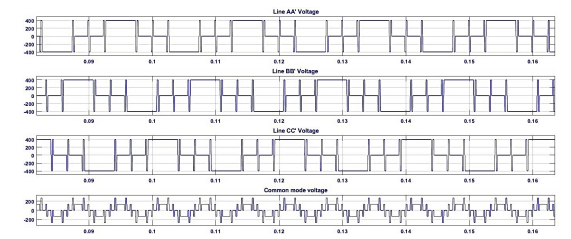

Figure 7: Line Voltages between Inverters with Proposed SHE PWM for Three Commutation Angles and common source

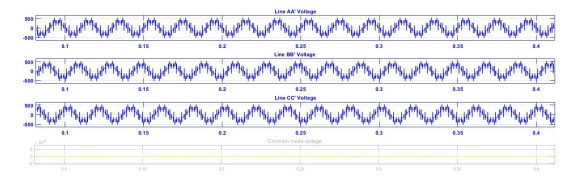

Figure 8: Line Voltages between Inverters with Proposed SHE PWM for three Commutation Angles and separate DC sources

Figs. 11-14 presents simulation outcomes acquired for the machine with Proposed SHE PWM for Five Commutation Angles. It indicates that through enforcing 


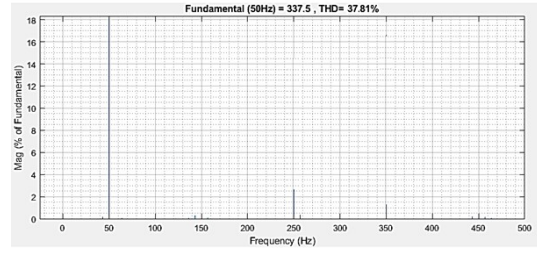

Figure 9: THD with Proposed SHE PWM for three Commutation Angles and common DC source

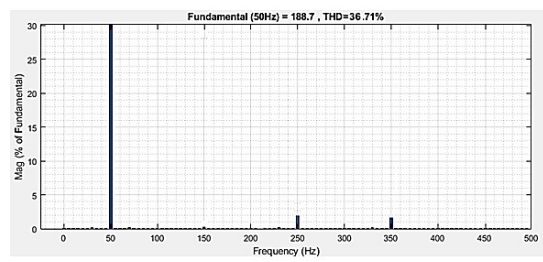

Figure 10: THD with Proposed SHE PWM for Three Commutation Angles for Separate DC sources

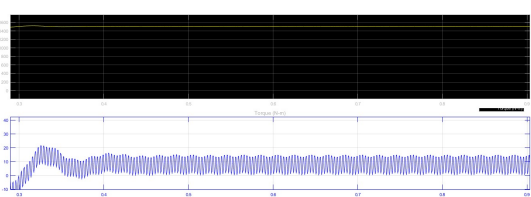

Figure 11: Torque with Proposed SHE PWM for three Commutation Angles and common DC source

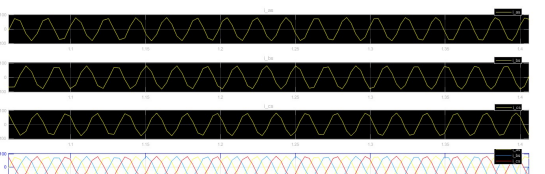

Figure 12: Stator currents with Proposed SHE PWM for three Commutation Angles and separate DC sources

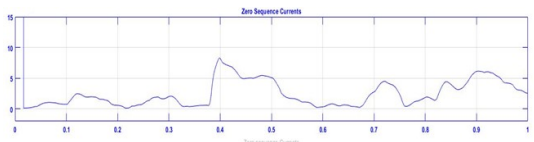

Figure 13: a. Zero sequence currents with Proposed SHE PWM for common DC source three Commutation Angles

five commutation angles the waveforms of inverter voltages have much less TH-D and much less third harmonics that the Z-SC reduced to $0.4 \mathrm{Amps}$. The TH-D is less in addition to Z-SC and Torque ripples, as compared to the ones shown in Figs. 7-10, because of the suppression of in more wide variety of Lower harmonic currents $\left(3^{\text {rd }}, 5^{\text {th }}, 7^{\text {th }}, 9^{\text {th }}, 11^{\text {th }}, 13^{\text {th }}, 15^{\text {th }}, 17^{\text {th }}\right)$. Evidently, Z-SC decreased and torque ripples min-

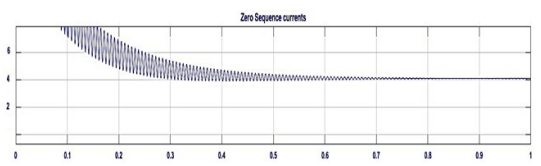

Figure 14: b. Zero sequence currents with Proposed SHE PWM for Separate DC sources and three Commutation Angles

imised in five commutation angles than three commutation angles.

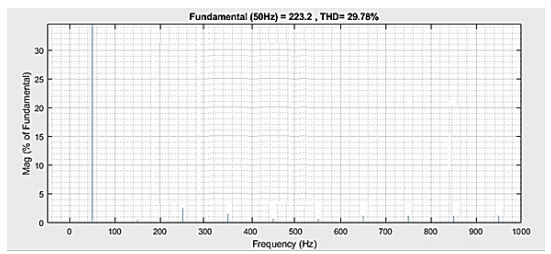

Figure 15: THD with Proposed SHE PWM for five Commutation Angles and common DC source

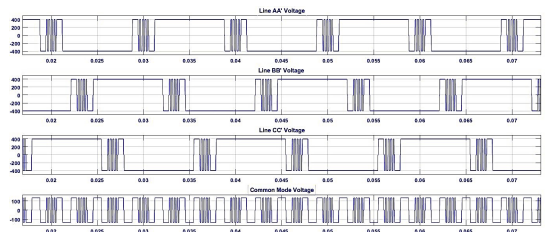

Figure 16: a.Line Voltages between Inverters with Proposed SHE PWM for five Commutation Angles and common DC source

\section{,

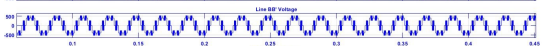 : : "W,}

Figure 17: b Line Voltages between Inverters with Proposed SHE PWM for Five Commutation Angles and separate DC sources

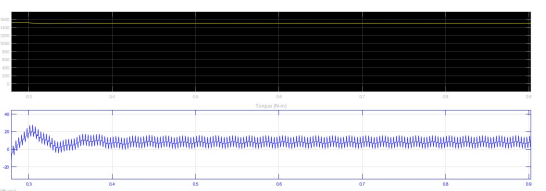

Figure 18: Torque with Proposed SHE PWM for five Commutation Angles and common DC source

sources as compared to single commonplace DC source proven in figs $7(\mathrm{~b})-14(\mathrm{~b})$ in both $3 \& 5 \mathrm{com}-$ mutation angles. But, Dual Inverter with separate DC 
angle

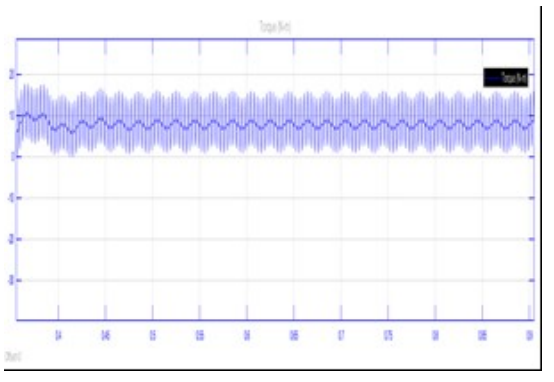

Figure 19: Torque with Proposed SHE PWM for five Commutation Angles and separate DC sources

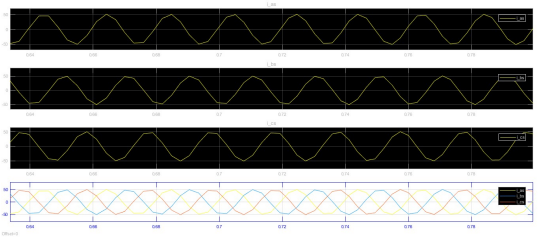

Figure 20: Stator currents with Proposed SHE PWM for five Commutation Angles and common DC source

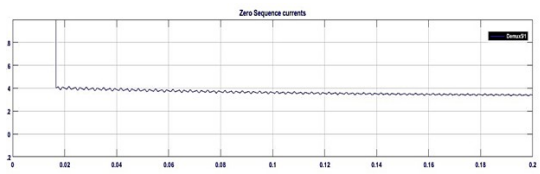

Figure 21: Zero sequence currents with Proposed SHE PWM for five Commutation Angles and common DC source

sources needs two batteries or DC sources and faces the common mode voltages problem. The primary aim of the implemented manipulate techniques in this paper is to regulate the Z-SC so that the torque ripples is minimised and TH-D reduced. Dual inverter feeding OEW-IM with common DC supply as well as separate Dc sources configurations with proposed GA primarily based SHE PWM scheme executed in both three-commutation angles and five commutation angles modes. In accordance to show the capability of suggested method when compared to the most current approach in dealing Z-SC, Torque ripples and TH-D at different Modulation index values. This evaluation suggests that, whilst Modulation Index $M$ is 0.9 , the conventional approach could lessens the rms value of ZSCC by $68.7 \%$ and the proposed approach reduced is $86.3 \%$. As soon as the modulation index is reduced to 0.6 , then $65.8 \%$ of reduction by conventional technique and it's miles $86.6 \%$ for the suggested method. From these results, it conveys that the proposed approach is superior to the current SHE approaches; furthermore, it may use by more wide range of switching

\section{Conclusions:}

In double inverter structure, feeding the inverters by a common DC source is very beneficious if Z-SC currents can be controlled. The same inverters and OEW-IM drive configuration with a single dc supply is better decision for several applications of electric drives. Meanwhile the source voltage of magnitude $\mathrm{V}_{\mathrm{dc}}$ a maximum voltage magnitude of $1.7 \mathrm{~V}_{\mathrm{dc}}$ can appreciated at the machine windings. So that a small rating battery used as the DC source which is a precise beneficial characteristic. This paper suggested a novel technique with SHE to reduce ripples in torque, Z-SC \& T-HD of open ended induction drive that also removes common mode circulation current thus facilitating double inverter to supply power from a nonisolated dc source. In addition, comparison of both the common Dc source and separate Dc sources connected to dual inverter structure is made in view of ripples in torque, ZS-C and TH-D by the proposed as well as conventional control technique. It is obvious that a common dc source arrangement has somewhat high ZS-C, TH-D and torque ripples than Separate DC sources arrangement as shown in Table.5. Common Dc Source structure has produced 0.43 amps and Separate Dc sources structure has produced 0.25 amps when controlled by the proposed SHE control technique. Therefore, with the proposed control method the common Dc source structure can perform close to that to separate Dc sources with less hardware requirements, cost and complexity of control. 


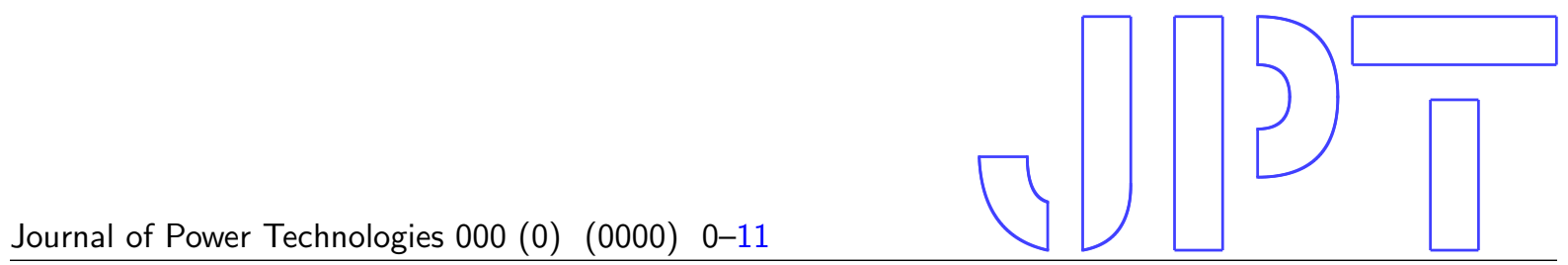

Conditions

Two
inverters
With
Separate
DC sources
modulated
By Conven-
tional
SHE PWM

Two

inverters

With

Separate

DC sources

modulated

By proposed

SHE PWM

Two
inverters
With
Single
DC source
modulated
By Conven-
tional
SHE PWM

Two inverters Single

DC source modulated By proposed SHE PWM
$357 \& 9$ considers in two inverters ( 5 angles)
$357,911131517 \& 19$ considers in two inverters (5 angles)

35 , considers in two inverters (3 angles)
$14.3 \mathrm{~N}-$

$\mathrm{m}$

$15.8 \mathrm{~N}-$

$\mathrm{m}$

$11.58 \mathrm{~N}-$ $\mathrm{m}$

17.97

$\mathrm{N}-\mathrm{m}$

16.4N-

$\mathrm{m}$

16.8

$\mathrm{N}-\mathrm{m}$

$357 \& 9$ considers in two inverters

(3 angles)

$357,911131517 \& 19$ considers in two inverters (5 angles)

Table 6: This is a caption

\section{References}

1.Barry Venugopal Reddy, V.T.S. (2013) .A Dual Inverter Fed Four-Level Open-End Winding In-

duction Motor Drive With a Nestedropectifier-

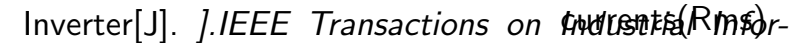
mattidㅇ, 9(2),938-946.

(Stator

current-32A

2.kiadehi, A.D., Drissi, K.E.K., and Prqquier, C. (2016) Angular Modulation of Dual-Inverter Fed Open-End Motor for Electrical Vehicle Applications. IEEE Transactions on Power Electronics, 31 (4), 2980-2990.

3.Welchko, B.A., Lipo, T.A., Jahns, T.M., and Schulz, S.E. (2004) Fault Tolerant Three-Phase AC

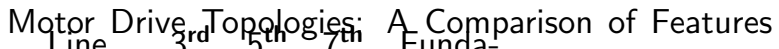
Cost, and Limitations. IEEE Pransactions on Power Electronics, 19 (4), 1108-1116.

ages

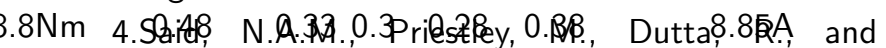
Fletcher, J.E. (2016) Torque ripple minimization in dual inverter open-end winding PMSM drives with

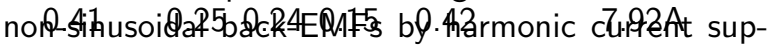
pression. IECON 2016 - 42nd Annual Conference of

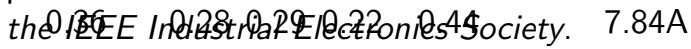

5.Rao, R.S., Chaitanya, B.N., Saichand, N., and Somasekhar, V.T. (2014) Comparative evaluation of SVPWM strategies for a dual inverter fed open-end winding induction motor drive with a single DC power supply. IECON 2014 - 40th Annual Conference of the
IEEEE2yndustriat Eolextromics Sogqipty.
$6.98 \mathrm{~A}$

6.Kalaiselvi, J., Sekhar, K.R.C., and Srinivas, S. (2012) Common mode voltage elimination PWMs for a dual two-level VS1 with single inverter switching. 2012 IEEE International Symposium on Industrial Electronics.

7.An, Q., Liu, J., Peng, Z., Sun, L., and Sun, L. (2016) Dual-Space Vector Control of OpenEnd Winding Permanent Magnet Synchronous Motor Drive Fed by Dual Inverter. IEEE Transactions on Power Electronics, 1-1.
$\begin{array}{llllll}0.39 & 0.28 & 0.26 & 0.18 & 0.39 & 8.23 \mathrm{~A}\end{array}$

8.Somasekhar, V.T., Srinivas, S., Reddy, B.P.,

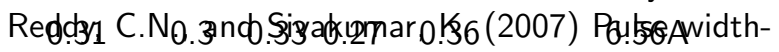
modulated switching strategy for the dynamic balancing of zero-sequence current for a dual-inverter fed open-end winding induction motor drive. IET Electric Power Applications, 1 (4), 591.

9.Wang, $Y_{0.2}$ Panda, $\mathrm{D}_{22}$ Lipo' T.A., and Pan, D. (2013) Open-Winding Power Conversion Systems Fed by Half-Controlled Converters. IEEE Transactions on Power Electronics, 28 (5), 2427-2436.

10.Senicar, F., Junge, C., Gruber, S., and Soter, S. (2010) Zero sequence current elimination for dual-inverter fed machines with open-end windings. IECON 2010 - 36th Annual Conference on IEEE Industrial Electronics Society. 
Current Reduction Method for Parallel HEPWM In-

11.Baiju, M.R., Mohapatra, K.K., Kanchan, R.S., and Gopakumar, K. (2004) A Dual Two-Level Inverter Scheme With Common Mode Voltage Elimination for an Induction Motor Drive. IEEE Transactions on Power Electronics, 19 (3), 794-805.

12.Hwang, J.-C., and Wei, H.-T. (2014) The Current Harmonics Elimination Control Strategy for Six-Leg Three-Phase Permanent Magnet Synchronous Motor Drives. IEEE Transactions on Power Electronics, 29 (6), 3032-3040.

13.Murai, Y., Watanabe, T., and Iwasaki, H. (1987) Waveform Distortion and Correction Circuit for PWM Inverters with Switching Lag-Times. IEEE Transactions on Industry Applications, IA-23 (5), 881-886.

14.Blaabjerg, F. (1994) An ideal PWM-VSI inverter using only one current sensor in the DC-link. Proceedings of 5th International Conference on Power Electronics and Variable-Speed Drives.

15.Attaianese, C., and Tomasso, G. (2001) Predictive compensation of dead-time effects in VSI feeding induction motors. IEEE Transactions on Industry Applications, 37 (3), 856-863.

16.Choi, J.-W., and Sul, S.-K. (1996) Inverter output voltage synthesis using novel dead time compensation. IEEE Transactions on Power Electronics, 11 (2), 221-227.

17.Munoz, A.R., and Lipo, T.A. (1999) On-line deadtime compensation technique for open-loop PWMVSI drives. IEEE Transactions on Power Electronics, 14 (4), 683-689.

18. Jeong, S.-G., and Park, M.-H. (1991) The analysis and compensation of dead-time effects in PWM inverters. IEEE Transactions on Industrial Electronics, 38 (2), 108-114.

19.Hwang, S.-H., and Kim, J.-M. (2010) Dead Time Compensation Method for Voltage-Fed PWM Inverter. IEEE Transactions on Energy Conversion, 25 (1), 1-10.

20.Oliveira, A.C., Jacobina, C.B., and Lima, A.M.N. (2007) Improved Dead-Time Compensation for Sinusoidal PWM Inverters Operating at High Switching Frequencies. IEEE Transactions on Industrial Electronics, 54 (4), 2295-2304.

21.Zhang, Y., Kang, Y., and Chen, J. The Zero-Sequence Circulating Currents between Parallel Three-Phase Inverters with Three-Pole Transformers and Reactors. Twenty-First Annual IEEE Applied Power Electronics Conference and Exposition 2006. APEC '06..

22.Chen, T.-P. (2012) Zero-Sequence Circulating verters Between AC Bus and DC Bus. IEEE Transactions on Industrial Electronics, 59 (1), 290-300.

23.Pan, C.-T., and Liao, Y.-H. (2008) Modeling and Control of Circulating Currents for Parallel ThreePhase Boost Rectifiers With Different Load Sharing. IEEE Transactions on Industrial Electronics, 55 (7), 2776-2785.

24.Ye, Z., Boroyevich, D., Choi, J.-Y., and Lee, F.C. (2002) Control of circulating current in two parallel three-phase boost rectifiers. IEEE Transactions on Power Electronics, 17 (5), 609-615.

25.Napoles, J., Leon, J.I., Portillo, R., Franquelo, L.G., and Aguirre, M.A. (2010) Selective Harmonic Mitigation Technique for High-Power Converters. IEEE Transactions on Industrial Electronics, 57 (7), 2315-2323.

26.Patel, H.S., and Hoft, R.G. (1973) Generalized Techniques of Harmonic Elimination and Voltage Control in Thyristor Inverters: Part I-Harmonic Elimination. IEEE Transactions on Industry Applications, IA9 (3), 310-317.

27.Enjeti, P.N., Ziogas, P.D., and Lindsay, J.F. (1990) Programmed PWM techniques to eliminate harmonics: a critical evaluation. IEEE Transactions on Industry Applications, 26 (2), 302-316.

28.Agelidis, V.G., Balouktsis, A., Balouktsis, I., and Cossar, C. (2006) Multiple sets of solutions for harmonic elimination PWM bipolar waveforms: analysis and experimental verification. IEEE Transactions on Power Electronics, 21 (2), 415-421.

29.Fei, W., Du, X., and Wu, B. (2010) A Generalized Half-Wave Symmetry SHE-PWM Formulation for Multilevel Voltage Inverters. IEEE Transactions on Industrial Electronics, 57 (9), 3030-3038.

30.Kavousi, A., Vahidi, B., Salehi, R., Bakhshizadeh, M.K., Farokhnia, N., and Fathi, S.H. (2012) Application of the Bee Algorithm for Selective Harmonic Elimination Strategy in Multilevel Inverters. IEEE Transactions on Power Electronics, 27 (4), 1689-1696.

31.Somasekhar, V.T., Gopakumar, K., and Shivakumar, E.G. (2002) A Space-Vector Modulation Scheme for a Dual Two-Level Inverter Fed Open-End Winding Induction Motor Drive for the Elimination of ZeroSequence Currents. EPE Journal, 12 (2), 1-19.

32. (2013) Symmetrical Induction Machines, in Analysis of Electric Machinery and Drive Systems, John Wiley \& Sons Inc., pp. 215-270.

33. Symmetrical Induction Machines. 
Journal of Power Technologies 000 (0) (0000) 0-11

34.Guzman, J.I., Espinoza, J.R., Moran, L.A., and Joos, G. (2010) Selective Harmonic Elimination in Multimodule Three-Phase Current-Source Converters. IEEE Transactions on Power Electronics, 25 (1), 44-53. 